\title{
Production and Financial Analyses of the Rotating Living Wall, an Urban Agricultural System
}

\author{
Jonathan Gumble, Robert Berghage, Dan Stearns \\ Department of Plant Science, The Pennsylvania State University, University Park, USA \\ Email: jjg5165@psu.edu
}

Received 31 July 2015; accepted 12 September 2015; published 15 September 2015

Copyright (C) 2015 by authors and Scientific Research Publishing Inc.

This work is licensed under the Creative Commons Attribution International License (CC BY). http://creativecommons.org/licenses/by/4.0/

c) (i) Open Access

\section{Abstract}

Experiments were performed from June 2014 to May 2015 at Penn State University's greenhouse facilities in order to understand the production capacities and financial viability of an innovative growing system referred to as the Rotating Living Wall produced by GreenTowers, a student innovation/entrepreneurship team. The system is a six-foot vertical conveyor that rotates troughs of microgreen plants to achieve even distribution of sunlight as well as relatively low maintenance within a minimal square foot area. Experiments were performed to understand differences in seasonal yields, differences in yields based on variety of microgreen, yield comparison to a traditionally grown microgreen control group; both on a yields per/trough method as well as a yields per/ft. ${ }^{2}$ method, rotational timing, moving versus stationary growth, differences in growth based on media depth, and differences in production yields from supplemental lighting. Performance criteria were based on measuring fresh weight, dry weight, height, and SPAD-meter readings (soil plant analysis development). Differences in yields throughout seasons were significant as well as differences between the Rotating Living Wall systems compared to a control group of traditional static greenhouse benches. The use of LED supplemental lighting provided significant differences in yields throughout winter season growing. Rotational timing, media depth, and physical movement of plants showed minimal or no significant influence on yields. By establishing the potential revenues and costs that were part of growing with the Rotating Living Wall system, financial viability was analyzed showing that these systems could be profitable when utilized in State College, PA, within certain operating parameters. The research completed throughout these studies has not only provided a baseline of operation for the systems but has also shown potential for the development of urban agricultural systems capable of aiding in the elimination of "food deserts" or urban neighborhoods and rural towns with limited food access.

\section{Keywords}

Urban Agricultural Systems, Rotating Living Wall, Food Deserts, Microgreens 


\section{Introduction}

The current world population consists of 7.2 billion people and is expected to reach over 9.5 billion by the year 2050 [1]. The Food and Agriculture Organization of the United Nations (FAO) has indicated that world hunger is significant and wide spread, stating "805 million people are estimated to be chronically undernourished in 2012-2014” [2]. Availability of food is not the only aspect of food security; access, stability, and utilization are components as well [3].

Considering the access component, the United States is considered food insecure due to the presence of "food deserts" which are "urban neighborhoods and rural towns without ready access to fresh, healthy, and affordable food” [4]. In 2013, approximately 14.3\% of US households were food-insecure [5]. Providing greater access to food throughout the United States has the potential to alleviate "food deserts" and raise awareness for access to fresh, healthy, and affordable food [5]. However, solutions still need to be developed.

The concept of "vertical farming” popularized initially by Dr. Dickson Despommier and his book, “The Vertical Farm” (2010) provides insight for potential solutions. The concept is essentially described as growing food on multiple floors within advanced skyscrapers. Advantages would include potential year round crop production, reduction or elimination in food transportation, and efficient growing practices [6]. Although these advantages would hold true for "vertical farming”, multiple issues would still preside, specifically significant initial capital investment and significant energy consumption [7]. Inspiration is provided for innovative growing through controlled environment agriculture practices or (CEA); defined as "the modification of the natural environment to achieve optimum plant growth" [8]. This is accomplished through the utilization of hydroponics, aquaponics, or aeroponics within some form of greenhouse structure [8]. One of the inherent aspects of CEA is the high initial capital investment as well as the higher operational costs compared to open field agriculture (OFA). Although this is inherently negative, the benefit that comes with CEA is significantly higher productivity [8].

Controlled environment agriculture (CEA) is utilized by multiple companies today. Skygreens [9], Verticrop [10], BrightFarms [11], and BrightAgrotech [12] are examples of innovative growing systems that utilize natural light, while FreightFarms [13], Podponics [14], Aerofarms [15], Green Sense Farms [16], and Mirai [17] utilize strictly artificial LED (light emitting diode) lighting. The realization of (CEA) is that the process can be energy intensive. Cost and energy analyses have been completed for case scenarios of growing lettuce and wheat indoors through the use of CEA, and have shown that not only would neither be profitable, but both would also create an excessive carbon footprint [18]. From these analyses, it can be shown that the only promising scenarios for producing food within urban environments is primarily through the use of natural light or alternative energy sources and also producing popular-trending or high value crops such as microgreens [19] having a potential market price of \$25 - \$50 per pound [20]. Urban farming additionally merits itself as having potential for providing food within urban environments [21]. However, the primary disadvantage associated with urban farming is its inability to produce significant quantities of food and also requiring space, time, and money; all being difficult to attain within today's cities for its specific purpose [22].

Effective and practical growing implementation for improving food access potentially resides in the integration of controlled environment agriculture and urban agriculture with the utilization of natural sunlight. Effectiveness of this particular growing implementation would also have a higher probability of success if initial capital investment remains relatively low, can be utilized in small or "unusable" spaces, and can produce trending niche food or crop items such as microgreens or organic produce with relatively low maintenance. There is a significant lack in scholarly work which investigates the entirety of financial and production aspects of a given agricultural production implementation system in a specific geographical area to understand the various aspects and nuances that determine the practicality and economic viability. Therefore, one system referred to as the “Rotating Living Wall” produced by GreenTowers LLC, “An Urban Agricultural Design Company” has been tested for the duration of one year in Penn State University’s greenhouse facilities to understand the production capacities, financial viability, and ultimately its potential for increasing food access.

\section{Experimental Procedure}

\subsection{Design and Construction}

The Rotating Living Wall is essentially a custom-built vertical conveyor system comprised of readily-available parts and components. An electric motor rotated the conveyor system, and a timer allowed for precision move- 
ment intervals. On each rung of the conveyor, hung an individual grow trough that could easily be taken on and off. The conveyor system's track comprised twelve rungs which could hold the equivalent twelve grow troughs.

\subsection{Production Experiments}

The intention of the experiments performed for the Rotating Living Wall prototypes was to understand the various factors that affect the performance and ultimately the production yields of a "vertical conveyor plant system" that utilizes primarily natural sunlight, while also understanding performance in a specific location throughout the duration of one year or four seasons. The factors tested included seasonal yields, growth in a vertical system vs. growth on a horizontal plane (light penetration), variety of crops, rotational timing, movement vs. stationary full media depth vs. half depth, and artificial lighting.

\subsubsection{Variety of Crops}

Due to the limited space within the Rotating Living Wall prototype, as well as the desire for financial viability, microgreens were chosen to be grown within the system. As stated, microgreens can be sold for $\$ 25-\$ 50$ per pound and can be harvested at only several inches tall; making them the ideal selection [23]. A variety of microgreens were chosen for these experiments, specifically, Basil (Dark Opal), Chinese Cabbage (Kogane), Choi Pac Choi (Red), Collard (Champion), Hon Tsai Tai, Kale (Toscano), Kohlrabi (Purple), Mizuna, Mustard (Red Rain), Radish (Daikon), Red Cabbage, and Tatsoi. By growing twelve types of microgreens, each variety could be grown in a single wall system trough within each growing trial, while also understanding which varieties were best suited based on production of greatest plant mass.

\subsubsection{Seasonal Yields}

The Rotating Living Wall was designed to function within a greenhouse enclosure to primarily utilize natural sunlight for growing. Due to its inherent design concept, the production yields of the system will fluctuate with the changing of seasons due to differences in temperature and light levels. Sixteen trials were completed; four in summer, four in fall, four in winter, and four in spring; essentially encapsulating an annual production "snapshot" of the system and the differences in production throughout the seasons.

\subsubsection{Growth in Vertical System vs. Growth on a Horizontal Plane (Light Penetration)}

The design of the Rotating Living Wall does produce shadowing within the system, limiting the amount of light available to the grow troughs, especially within certain trough positions located near the bottom or back sections. Of the sixteen trials testing the walls, twelve trials incorporated growing the equivalent number of grow troughs on a traditional flat surface for comparison (trials in summer, fall, and spring).

\subsubsection{Rotational Timing}

The Rotating Living Wall was capable of turning at various intervals throughout the day to achieve even distribution of sunlight for the grow troughs within the system. To understand the effects of different rotational rates, each wall was attached to a separate timer. Wall 1 rotated the slowest; one trough position per seven hours. Wall 2 rotated the second slowest at one trough position every 5 hours. Wall 3 rotated one trough position every 3 hours, and Wall 4 rotated one trough position each hour. This procedure was done for the summer and fall for a total of eight trials.

\subsubsection{Movement vs. Stationary}

In addition to the presence of shading, the Rotating Living Wall also "moved" the plants growing within the system. To understand potential effects of the physical movement itself, a bench was constructed to oscillate a portion of the flat troughs in the four summer trials.

\subsubsection{Full Media Depth vs. Half Depth}

The cost of growing media is a significant cost in microgreen production. Therefore the amount of media required to support adequate growth, but no more should be used. In the fall and spring trials, half of the flat troughs utilized for comparison of wall production had foam-board inserts to replicate the conditions of halffilled media troughs. 


\subsubsection{Artificial Lighting}

By the end of fall trials, it was evident that substantial yields could no longer be achieved through the limited sunlight available. Therefore, just the walls were tested in the winter season with different types of artificial lighting, specifically, no lighting, fluorescent, metal halide, and LED (Light Emitting Diode). In spring trials, LED and metal halide lighting were still being tested. However, fluorescent lighting was replaced by white colored grow troughs to understand if the reflective properties of the surface could enhance light penetration and ultimately potential yields of the system.

\subsection{Layout}

The following experimental setup was constructed within the Tyson greenhouses at the Pennsylvania State University in University Park, PA to test for annual production as well as multiple production factors within a year's time frame (Figure 1).

The layout (Figure 2) was altered each season to allow for different factors to be tested. In the summer, fall, and spring growing seasons, four wall systems each holding a total of twelve grow troughs (48 grow troughs total) were tested while also testing 48 flat control grow troughs. In the winter growing season just the walls were tested for various forms of supplemental lighting, therefore resulting in the following configurations:

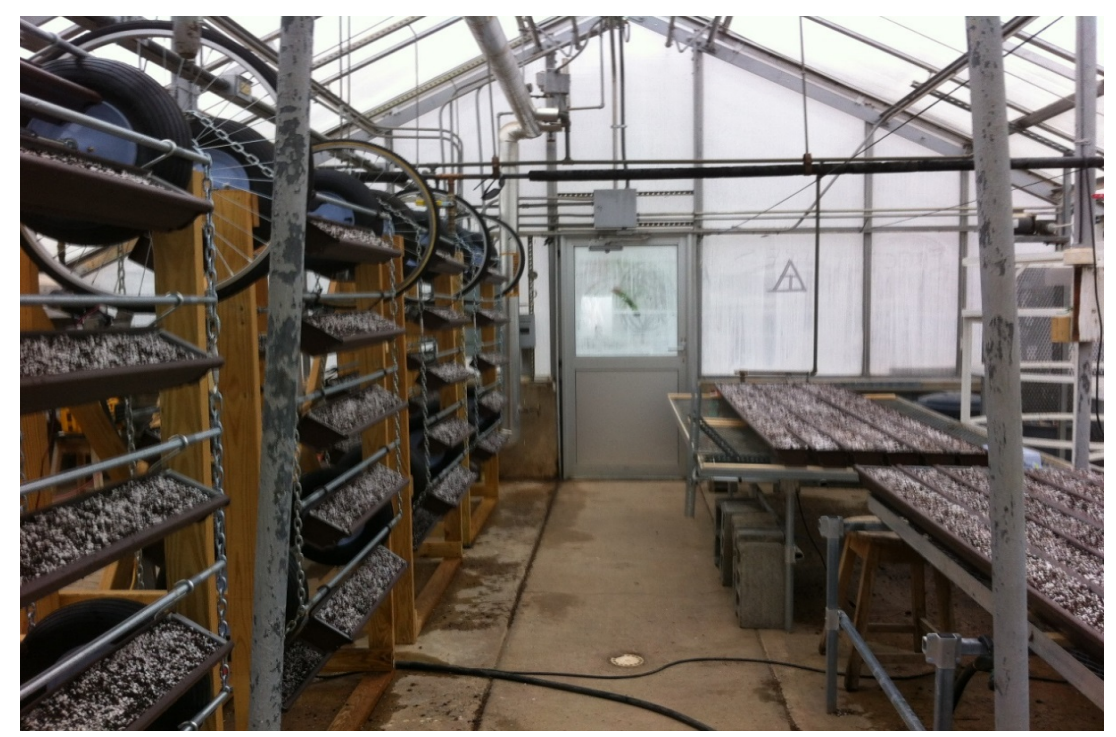

Figure 1. Greenhouse setup.

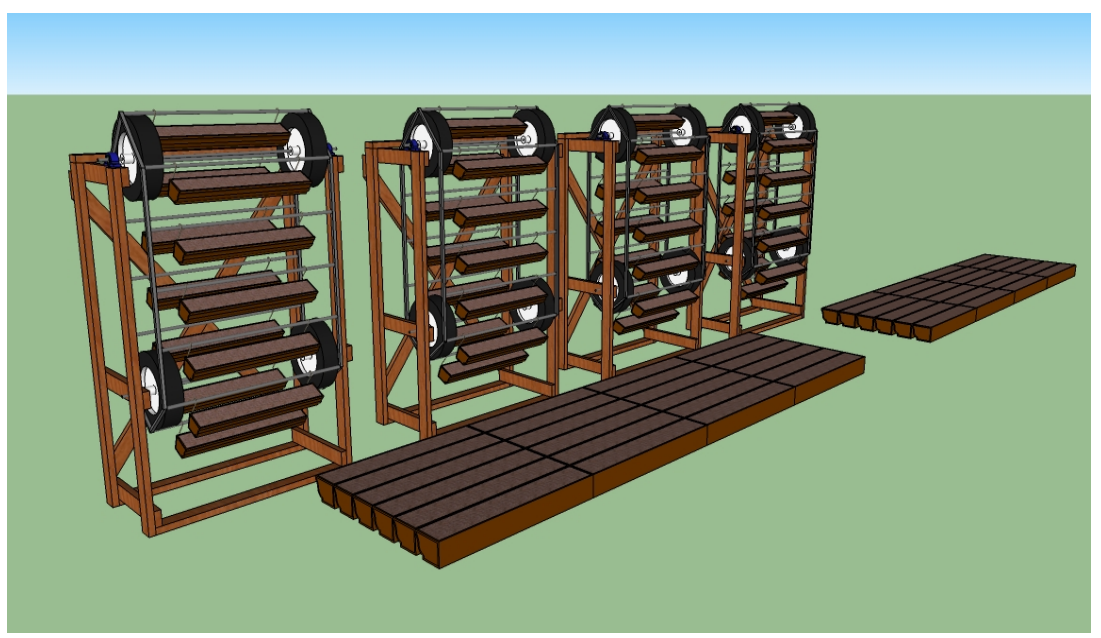

Figure 2. SketchUp model of experimental layout. 
Summer:

96 troughs total; 48 troughs in wall systems and 48 flat troughs;

4 walls of 12 rotating at different rates; 2 groups of 24 flat troughs;

One group stationary; one group oscillating.

Fall:

96 troughs total; 48 troughs in wall systems and 48 flat troughs;

4 walls of 12 rotating at different rates; 2 groups of 24 flat troughs;

One group filled completely with media; one group half-filled with media.

Winter:

48 troughs total; 4 walls of 12; one with no lighting, one with fluorescent lighting,

One with metal halide lighting, one with LED lighting.

Spring:

96 troughs total; 48 troughs in wall systems and 48 flat troughs;

4 walls of 12; one with no lighting, one with white colored troughs, one with metal halide lighting,

One with LED lighting; 2 groups of 24 flat troughs;

One group filled completely with media; one group half-filled with media.

\subsection{Process}

\subsubsection{Seeding}

Accurate seeding was required throughout the trials to maintain consistency, and the standard recommended seeding rate for microgreens according to Johnny's Seeds is approximately 1/2" spacing or less [23]. Each grow trough had a footprint of approximately 1.165 square feet, and at 1/2" spacing, 336 seeds were required per trough. In order to maintain this consistency and accuracy, a vacuum seeder was constructed that consisted of a twelve gallon shop vacuum cleaner, nylon tubing, and PVC pipe with 28 plastic pipette tubes. Twelve "passes" would essentially seed a single trough and could be completed within three minutes.

\subsubsection{Growing}

The variety of microgreens chosen were categorized as fast growing from Johnny's Seeds and had a recommended growing period of 10 - 15 days. The full 15 days were chosen as the growing period and kept consistent throughout the trials; allowing comparisons to take place [22]. SunGro Sunshine Mix 4 Aggregate Plus was utilized as the growing media for these experiments.

\subsubsection{Harvesting}

After the 15 day growing period was complete, each trough of microgreens was harvested. A jig and hopper allowed the microgreens to be collected into a bag quickly and efficiently by means of a battery operated hedge trimmer.

\subsection{Performance Criteria}

To understand the performance of the microgreens grown within the trials and analyze the various treatments, four criteria were utilized; fresh weight (harvested product), dry weight, height, and SPAD (soil plant analysis development) (a measure of chlorophyll and nitrogen status) [23]. Fresh weight was measured as soon as harvesting was completed by weighing each sample. Dry weight was measured approximately one week after harvest. Samples were dried in a forced air circulation drying oven at $60^{\circ} \mathrm{C}$. 5 sub-sample measurements were taken from each trough to estimate height. A tape ruler with cm markings was used to measure each microgreen sub-sample from the surface of the media to the highest point of the plant. (480 readings for 96 troughs or one trial) 5 sub-sample measurements were taken from each trough for SPAD. (480 readings for 96 troughs or one trial.)

A SPAD meter essentially serves as a chromometer and gives an estimate of chlorophyll content to understand the health and vigor of plants [23].

Statistical analysis was performed through the use of Minitab 17 statistical analysis software. ANOVA or analysis of variance was utilized with a $95 \%$ confidence interval for analyzing all data. 


\subsection{Financial Analysis}

Not only were the production figures obtained throughout the year of trials, but the financial figures as well to understand if the Rotating Living Wall could be profitable and ultimately practical. Microgreens can have a selling point of $\$ 25$ - \$50/pound [22]. However, this is only in particular niche markets. In many areas, the demand at this price point would not exist and in a more rural area, a market price of $\$ 15 /$ pound or less could be considered more reasonable. When understanding the profitability of microgreen production, one of the key factors is simply the market price that can be attained, which ultimately determines profitability. For the following case studies based on the data collected throughout the Rotating Living Wall experiments, \$15/pound, \$25/pound, and \$50/pound were considered.

The other aspects evaluated were the costs associated with production. These costs included materials (media and seeds), utilities (electricity for motors, lighting, and heating), and the cost of labor required for operations. For the case study performed, one Rotating Living Wall unit operating for one year within State College, Pennsylvania was considered, and the data collected for all twelve microgreen varieties was used for the financial analysis.

Lighting was also analyzed in terms of the costs of operation. Testing occurred for two fluorescent fixtures, one metal halide light fixture, and one LED light fixture. Light output was completed through the use of a light meter (Apogee Instruments' Model QMSW-SS) and energy consumption testing was completed through the use of an energy consumption meter (P3 International, Kill A Watt EZ, Model P4460).

\section{Results and Discussion}

\subsection{Production Experiments Results}

The following data, figures, and information show the results for the factors tested based on the performance criteria of fresh weight, dry weight, and length and SPAD recordings.

\subsubsection{Growth in Vertical System vs. Growth on a Horizontal Plane (Light Penetration)}

Fresh Weight: The amount of harvestable product or fresh weight was significantly different (higher) for the microgreens grown in flat troughs throughout the growing trials. This was likely due to the lower light levels or lesser light penetration that is conditional of the wall systems. Throughout twelve trials of growing, it was calculated that the wall system on a per trough basis produced $79 \%$ of fresh weight compared to the flat troughs (Figure 3).

Dry weight was significantly different (higher) for the microgreens grown in the flat troughs throughout the growing trials as well. This was likely again due to the lower light levels or lesser light penetration that is conditional of the wall systems. Throughout twelve trials of growing, it was calculated that the wall system on a per

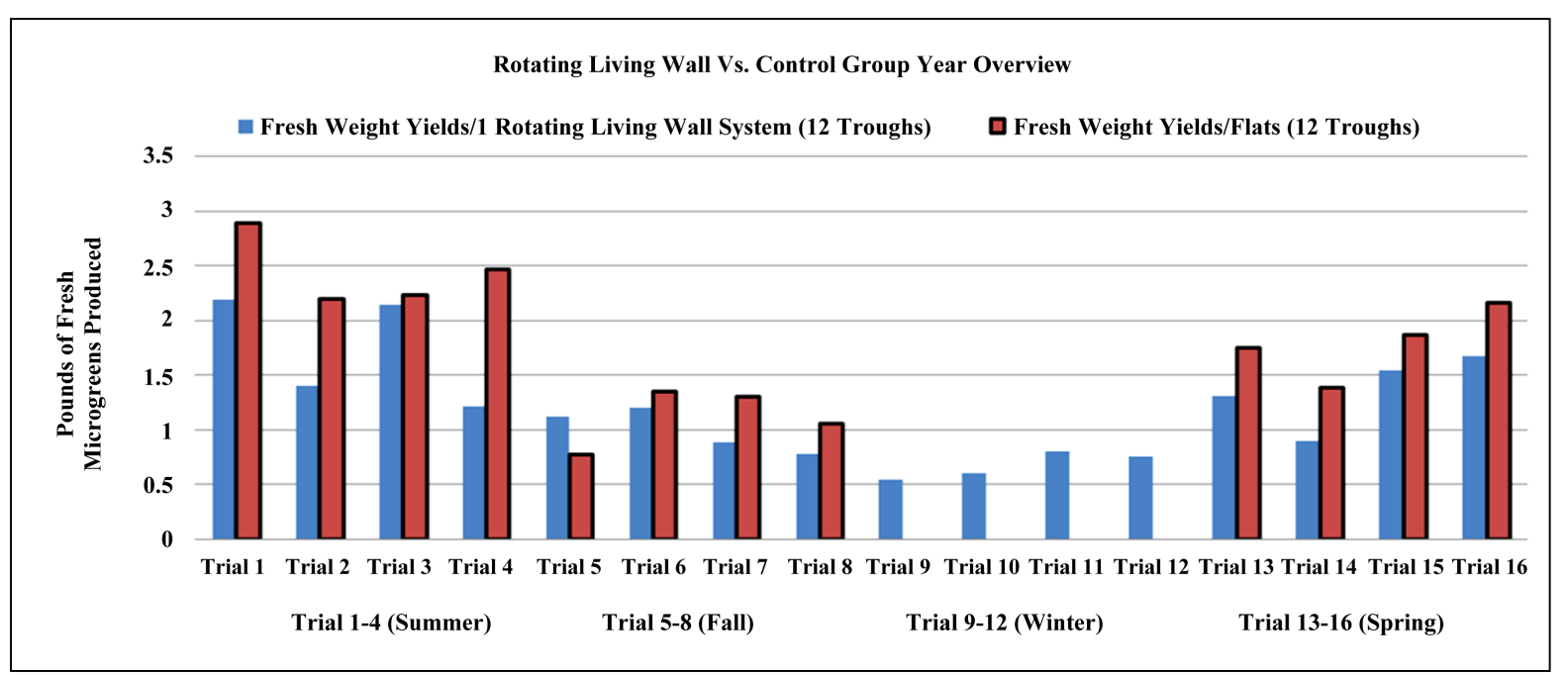

Figure 3. Annual production overview of fresh harvestable product (rotating living wall vs. control). 
trough basis produced approximately $74 \%$ of dry weight compared to the flat troughs. The average length of microgreens grown in the flat troughs compared to the wall systems was significantly different; specifically that microgreens grown in the flat troughs were taller. Due to the higher light levels found in the flat troughs, these microgreens grew larger, therefore taller. The average SPAD readings taken from the microgreens grown in the flat troughs were significantly different (higher) compared to those obtained from the microgreens grown in the wall systems. This can be explained through higher chlorophyll contents of the microgreens resulting from greater amounts of light received in the flat troughs.

\subsubsection{Production per Trough vs. Production per Square Foot}

Although growing with the traditional flat environment (control) produced more microgreens per trough unit, another measurement that needs to be considered is the production of microgreens per square foot of greenhouse area. With the Rotating Living Wall system, more troughs can fit within a square footage, making the production per square foot significantly greater than traditional flat growing. Figure 4 shows the ratio of pounds of fresh microgreens grown per square foot by the wall systems to the pounds of fresh microgreens grown per square foot by the flat trough control group for each trial. On average, the wall systems produced 2.25 times the fresh weight of microgreens per square foot compared to the control troughs (based on $4.66 \mathrm{Ft}^{2}{ }^{2}$ wall system).

\subsubsection{Crop Performance Based on Variety of Microgreen}

Differences in growth characteristics were significant when comparing the varieties of microgreens in regard to fresh weight, dry weight, length, and SPAD. Therefore, different varieties of microgreens will affect yields and ultimately the performance of the Rotating Living Wall. These differences in fresh weight can be seen below both in the wall systems as well as the (control) flat troughs (Figure 5).

\subsubsection{Rotational Timing}

There was no significant effect of rotational timing on any of the evaluated factors. Throughout the eight trials evaluated, no significant differences were evident in regard to fresh weight, dry weight, length or SPAD. When observing entire production of the wall systems for eight trials, each system produced approximately 11 pounds of microgreens; varying only by approximately half of a pound. There were minimal differences in dry weight as well.

\subsubsection{Movement vs. Stationary}

No significant differences were evident in fresh weight, dry weight, length, or SPAD when comparing moving and stationary flat treatments.

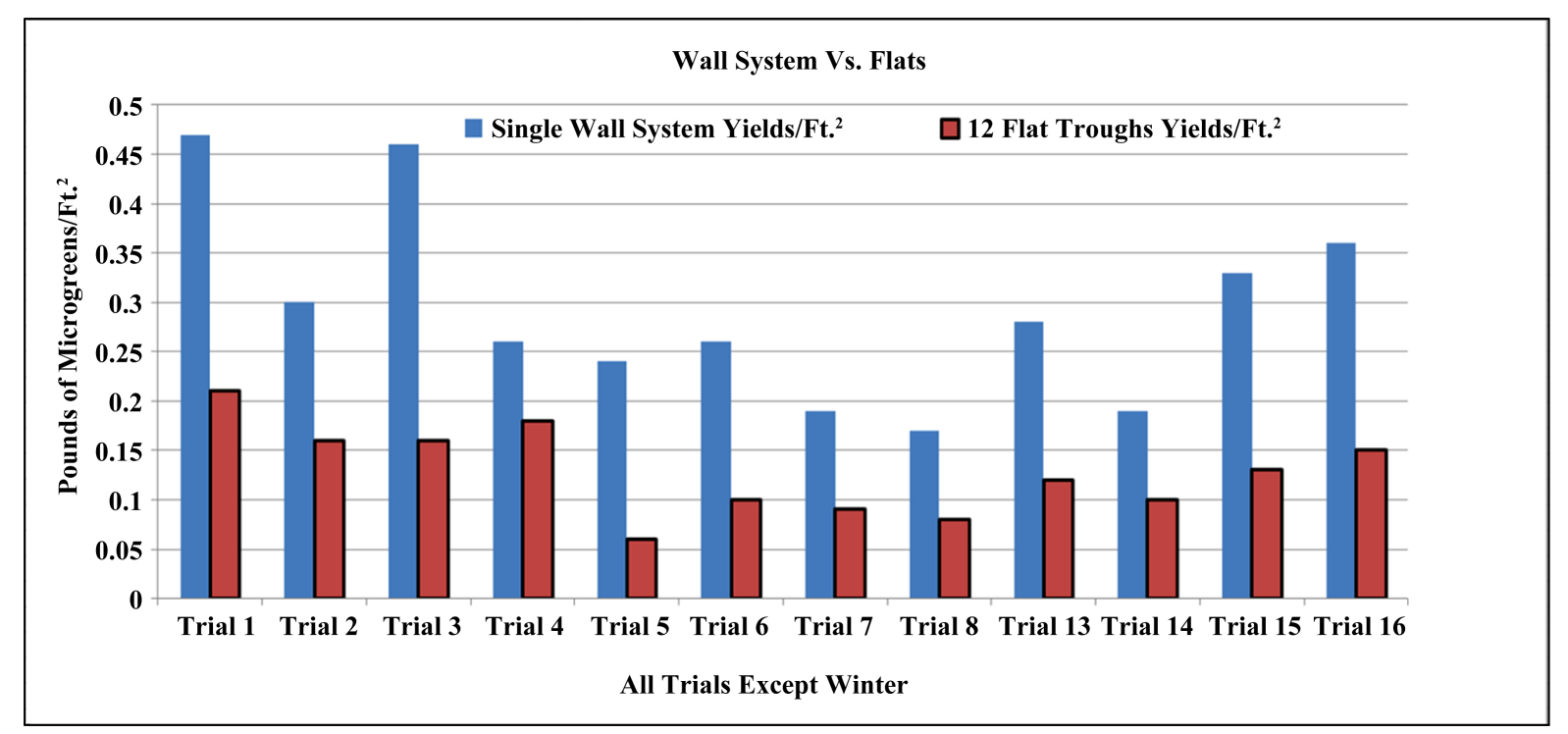

Figure 4. Annual production overview of fresh weight (production/Ft. ${ }^{2}$ comparison) (rotating living wall vs. control). 


\subsubsection{Full Media Depth vs. Half Depth}

Significant difference was found in terms of fresh weight with the deeper troughs producing the higher fresh weight yields (Figure 6). However, when considering that the average difference in production between the two treatments was only 10 grams from using only half the amount of media, it would be logical from a financial standpoint to utilize half-filled media troughs to reduce costs. One bale of Sungro Sunshine \#4 Mix Aggregate Plus (3.8 cu.ft.) costs $\$ 33.60$ and will fill 24 troughs completely. This is equivalent to $\$ 1.40$ per trough. By only using half the volume of media for each trough, the cost is reduced to $\$ 0.70$ per trough. Significant difference was found in length comparison and can mostly be attributed to the microgreens having a larger reservoir of water within the deeper media. Differences in dry weight as well as SPAD readings were not significant.

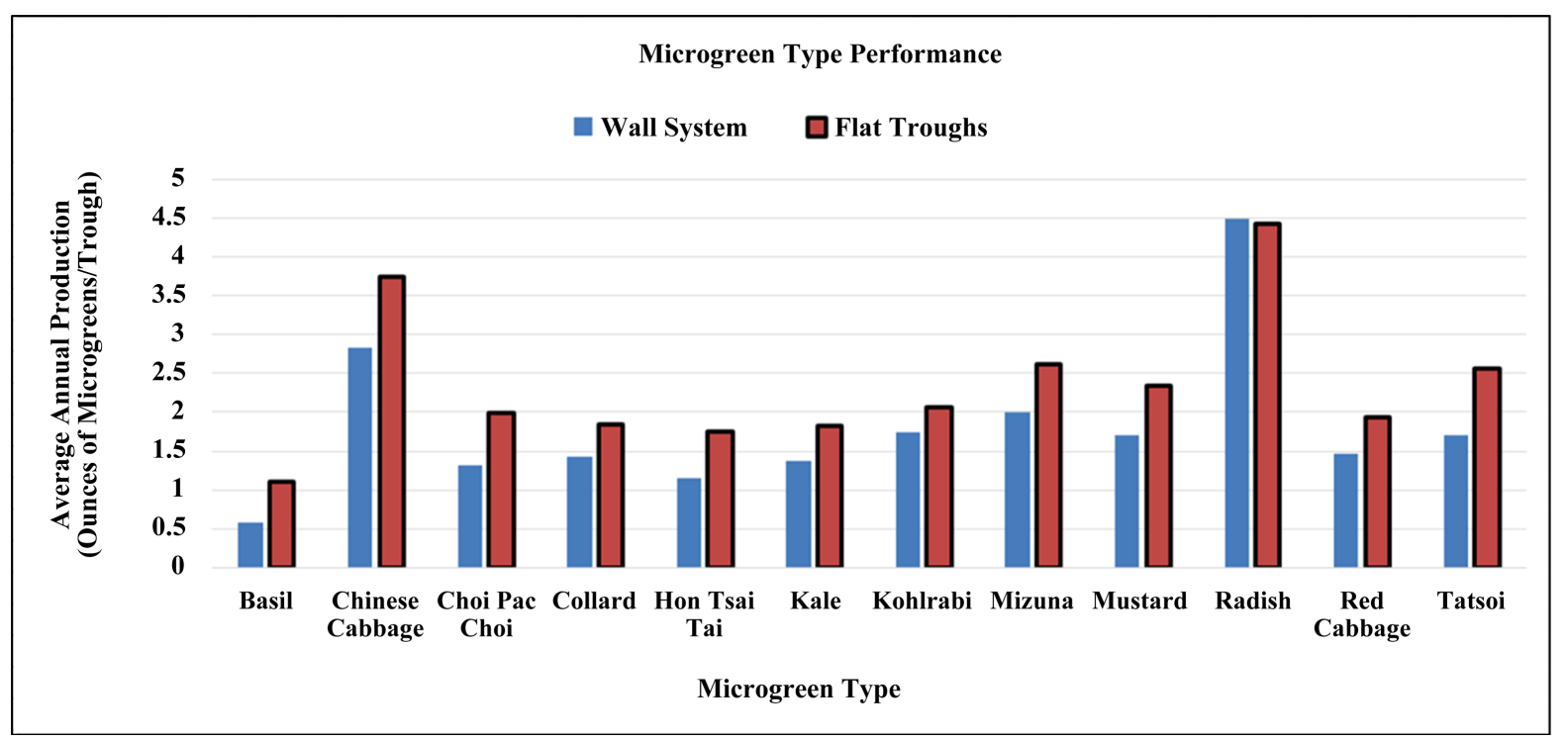

Figure 5. Annual microgreen variety performance overview (trough basis).

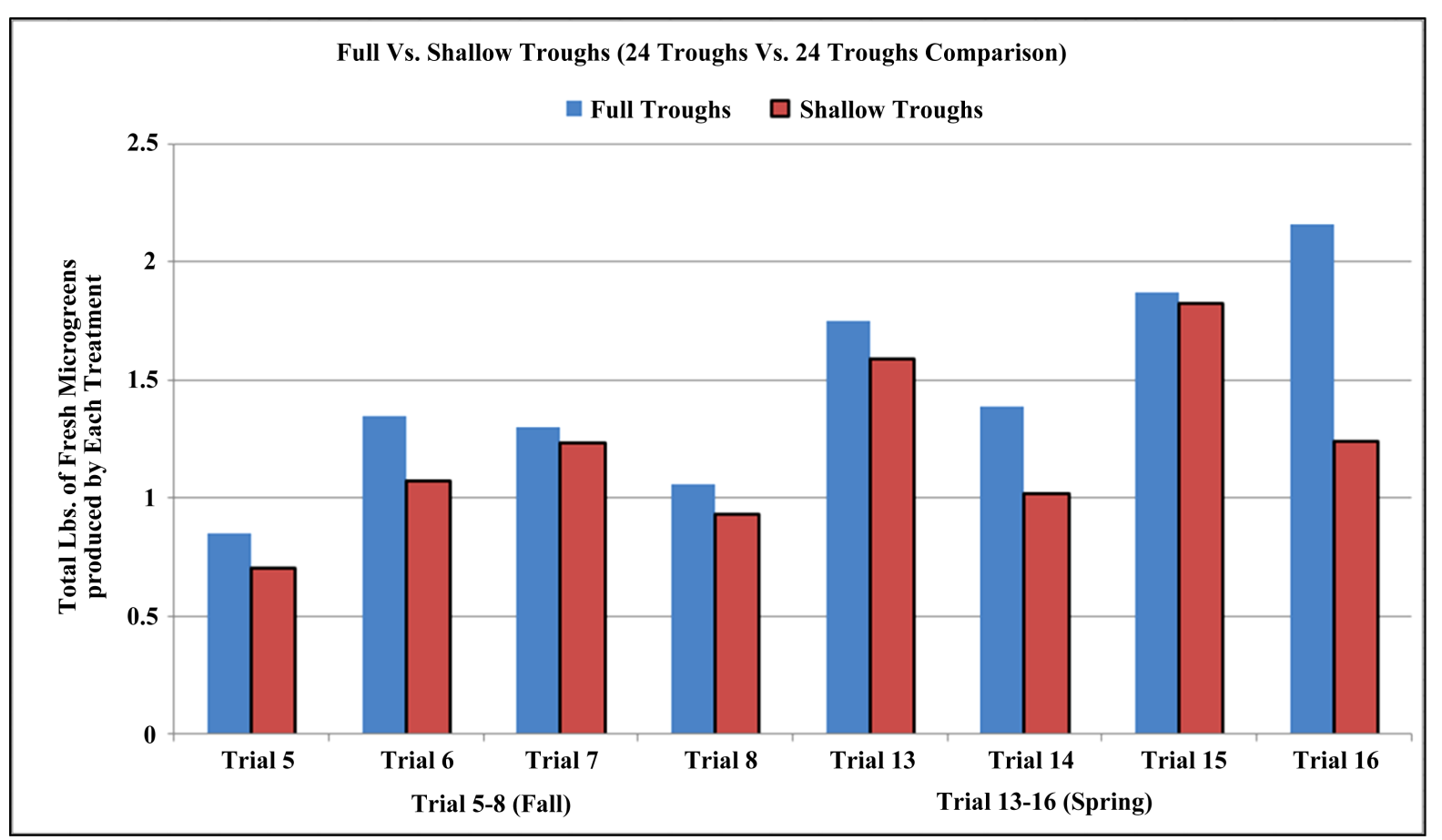

Figure 6. Differences in fresh weight based on media (full trough 3.5”, shallow trough 1.75”). 


\subsubsection{Artificial Lighting}

Significant differences in fresh weight were found with LED lighting producing the greatest yields, followed by metal halide, fluorescent, and lastly no lighting at all (Figure 7). Significant differences in dry weight were found as well following the same progression. Differences in length and SPAD readings were not significant.

In the spring trials, the wall systems were tested once more for differences in production yields based on the use of LED lighting, metal halide lighting, no lighting, and in place of fluorescent lighting, gloss white gutter grow troughs. Significant differences in fresh weight were found with LED lighting producing the greatest yields, followed by metal halide, the white grow troughs, and lastly no lighting at all (Figure 8). Differences in length as well as SPAD readings were not significant.

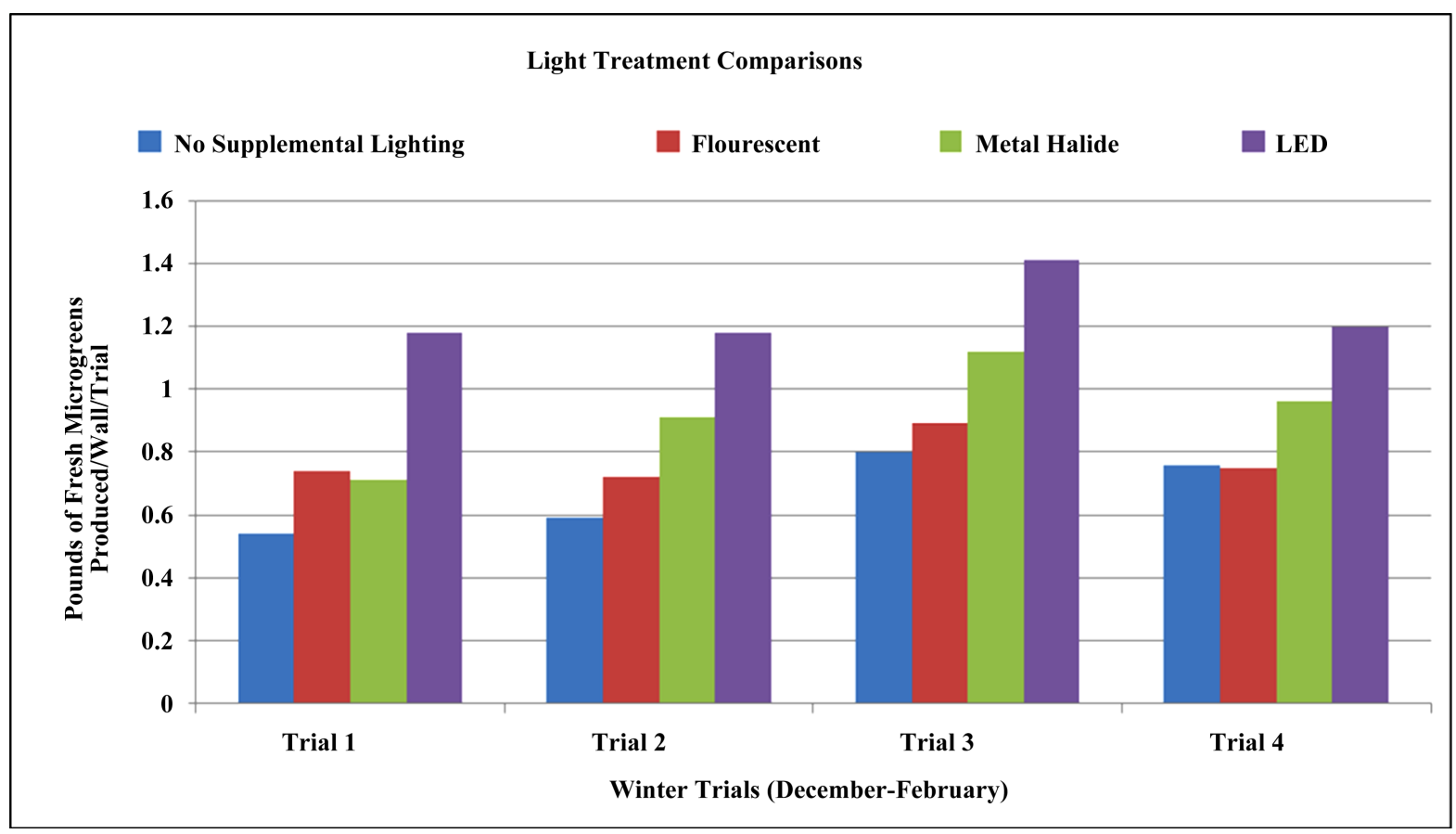

Figure 7. Differences in fresh weight based on lighting type.

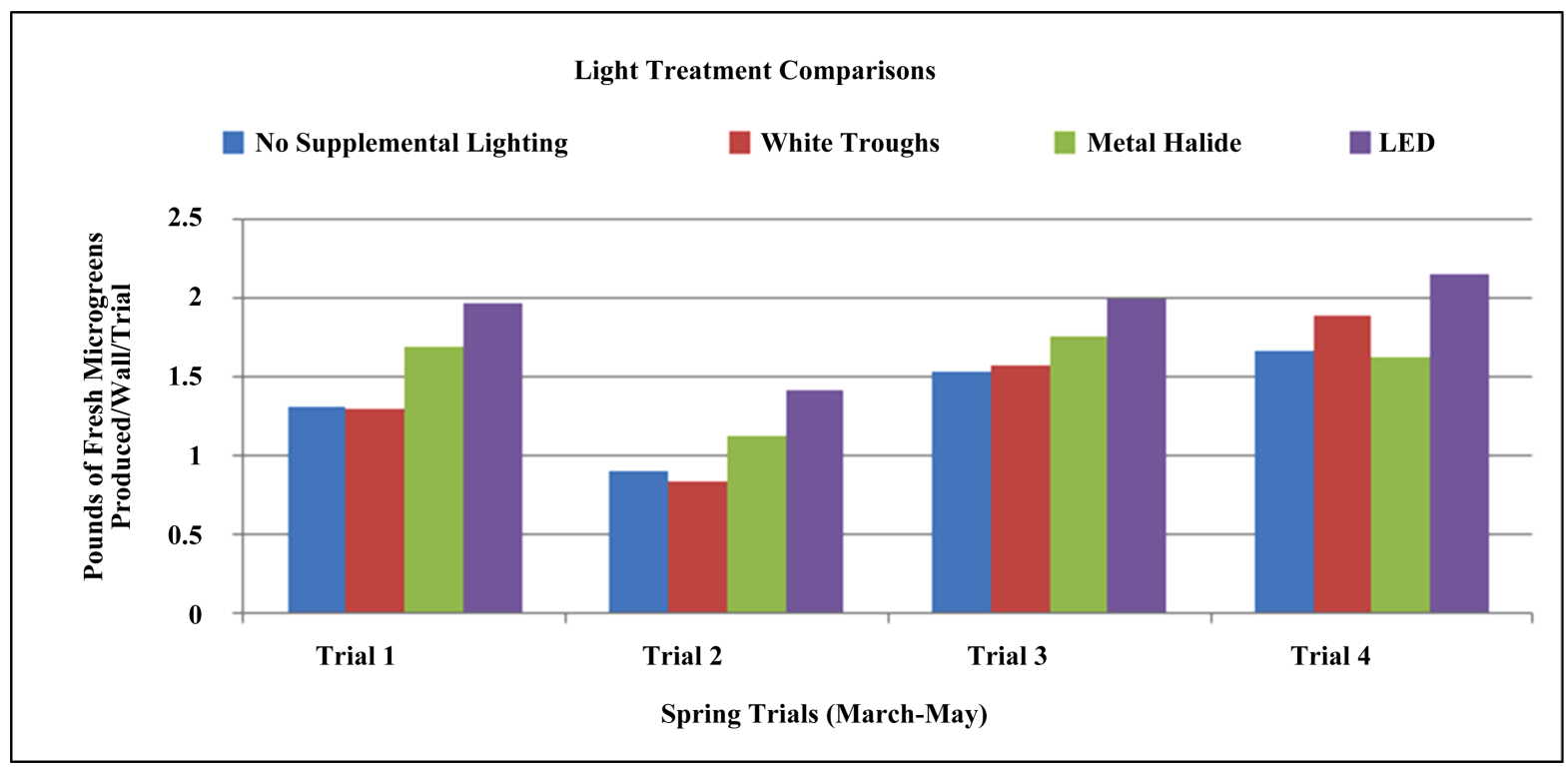

Figure 8. Differences in fresh weight based on lighting treatment (spring trials). 


\subsection{Financial Analysis Results}

\subsubsection{Revenue}

The total microgreen fresh weight produced within one year from one Rotating Living Wall system in State College, PA totaled 19.06 pounds. Keeping with 19.06 pounds as the expected average annual production for a wall system operating within $4.66 \mathrm{ft}^{2}$, the following potential revenues are calculated:

$\begin{array}{ll}\text { \$15/pound: \$285.90/year } & \text { \$61.35 revenue/ft. }{ }^{2} / \text { year } \\ \text { \$25/pound: \$476.5/year } & \text { \$102.25 revenue/ft. }{ }^{2} \text { /year } \\ \text { \$50/pound: \$953/year } & \text { \$204.51 revenue/ft. }{ }^{2} \text { year }\end{array}$

\subsubsection{Costs}

When calculating costs, several assumptions need to be made regarding operations.

SunGro Sunshine Mix 4 Aggregate Plus was used as the growing media and can be purchased at $\$ 33.60 / 3.8$ cu. ft. bale if purchased in bulk; quoted from Griffin Greenhouse Supplies. One bale is able to fill 24 troughs completely.

Seed costs were based on the purchased costs for the twelve types of microgreen seeds used throughout the experimental trials (supplied by Johnny's Seeds). Approximately 336 seeds were utilized for each growing trough.

Electricity costs for the rotational motion provided by the 20 watt motor were based on 8 cents/kWh and 2 hour rotation intervals at 10 seconds of movement for each movement (12 rotations). Therefore,

(20 W or $0.02 \mathrm{Kw}) *(120$ seconds or 0.03 hours $) *(8$ cents $/ \mathrm{kWh}$ or $\$ 0.08 / \mathrm{kWh})$

$=\$ .000048 /$ day or approximately $\$ .02 /$ year

Heating costs were calculated from the greenhouse energy cost estimator by Greenhouse.

Engineering NRAES-33 Robert Aldrich and John Bartok. The Rotating Living Wall can fit within an enclosure approximately $1.2^{\prime} \times 4^{\prime} \times 8^{\prime}$. The advantage to this configuration is that the whole growing apparatus can be positioned so the back side can be directly against the south wall of a building or similar type structure. This significantly reduces heat loss and still allows for good light exposure.

The labor involved with the operations of one "Rotating Living Wall" consisted of media prep work, seeding, watering, and harvesting. Therefore, the estimated time for each of these labor components would be the following; media prep: 30 minutes, seeding: 15 minutes, watering: 15 minutes, and harvesting: 30 minutes.

The cost of this labor time ultimately depends on the hourly rate of the worker being paid. Due to the relative simplicity of the labor; $\$ 8 /$ hour could be justified.

Based on these assumptions, the following costs are associated with the operating a single Rotating Living Wall:

Materials:

Media \$1.40/trough

192 troughs/year $\quad \$ 268.80$

Seeds $\$ 0.12 /$ trough

192 troughs/year \$23.04

Utilities:

Electricity for motor $\$ 0.00005 /$ trough

192 troughs/year $\quad \$ 0.02$

Heating \$0.40/trough

192 troughs/year $\quad \$ 76.80$

Labor:

1.5 hours at $\$ 8 /$ hour for one grow period

16 grow periods/year $\$ 256$

Total Costs

192 troughs/year $\quad \$ 624.66$

\subsubsection{Profit Potential of Current Model}

With these associated costs, economic viability of one Rotating Living Wall operating for a year within State College, Pa or area of similar climate and light levels can only be profitable if the microgreen demand is $\$ 50 /$ pound or greater. At this price point, there is a $\$ 328.34$ annual profit for one wall system; (\$70.46 profit/ft. ${ }^{2} /$ year).

\subsubsection{Business Potential}

From this single case study, it can be seen that operating a business solely from producing microgreens with 
these systems would most likely not be viable due to the high operating costs especially in regard to labor and media. However, producing microgreens as a hobby by an individual with a single system does have potential for profitability even with relatively low price points for microgreens. Lastly, to make a microgreen production business viable through the use of the "Rotating Living Wall" systems, the use of growing media would have to most likely be replaced with a hydroponic or other form of nutrient system for lower operating costs and maintenance, and/or labor would have to be significantly reduced and replaced through automated systems; vacuum seeders, automatic harvesting machines etc. Although requiring significant upfront capital investment, this would allow for lower operating costs over time for potentially a much larger operation where profitability would have greater potential to be achievable.

\subsubsection{Costs of Infrastructure}

A fully functioning and enclosed Rotating Living Wall produced by GreenTowers retails for approximately $\$ 1500$, and occupies $8 \mathrm{ft}^{2}$; equivalent to $\$ 188 / \mathrm{ft} .{ }^{2}$. According to Tim Coolong's extension article, "Microgreens", from the University of Kentucky, greenhouse space can be constructed at a range of $\$ 8-\$ 30 / \mathrm{ft}^{2}$ and high tunnels even lower at $\$ 1.50 / \mathrm{ft}^{2}{ }^{2}$. With this being evident, it can be assumed that the Rotating Living Wall System can only be financially justified within areas where space is limited such as urban environments or cities. In undeveloped areas, it would be logical to grow over a larger area and simply utilize a high tunnel covering (Coolong, 2012).

\subsubsection{Financial Analysis of Artificial Lighting}

From the chart (Figure 9), it can be shown that there is a significant increase in fresh weight production from the utilization of supplemental lighting, especially LED.

The average difference in production of fresh weight between the wall system with LED lighting and the wall system without any supplemental lighting was approximately 0.57 pounds per growing trial. The 250 watt LED lighting throughout the growing trials was turned on for 16 hours a day. The cost for this light usage can be calculated:

$$
\text { (250 W or } 0.25 \mathrm{KW}) *(16 \text { hours }) *(8 \text { cents } / \mathrm{kWh} \text { or } \$ 0.08 / \mathrm{kWh})=\$ 0.032 / \text { day }
$$

Therefore, the cost of lighting one system for the duration of 15 days costs a total of $\$ 4.80$. An increase in 0.57 pounds of microgreens can result in the following increase in revenue:

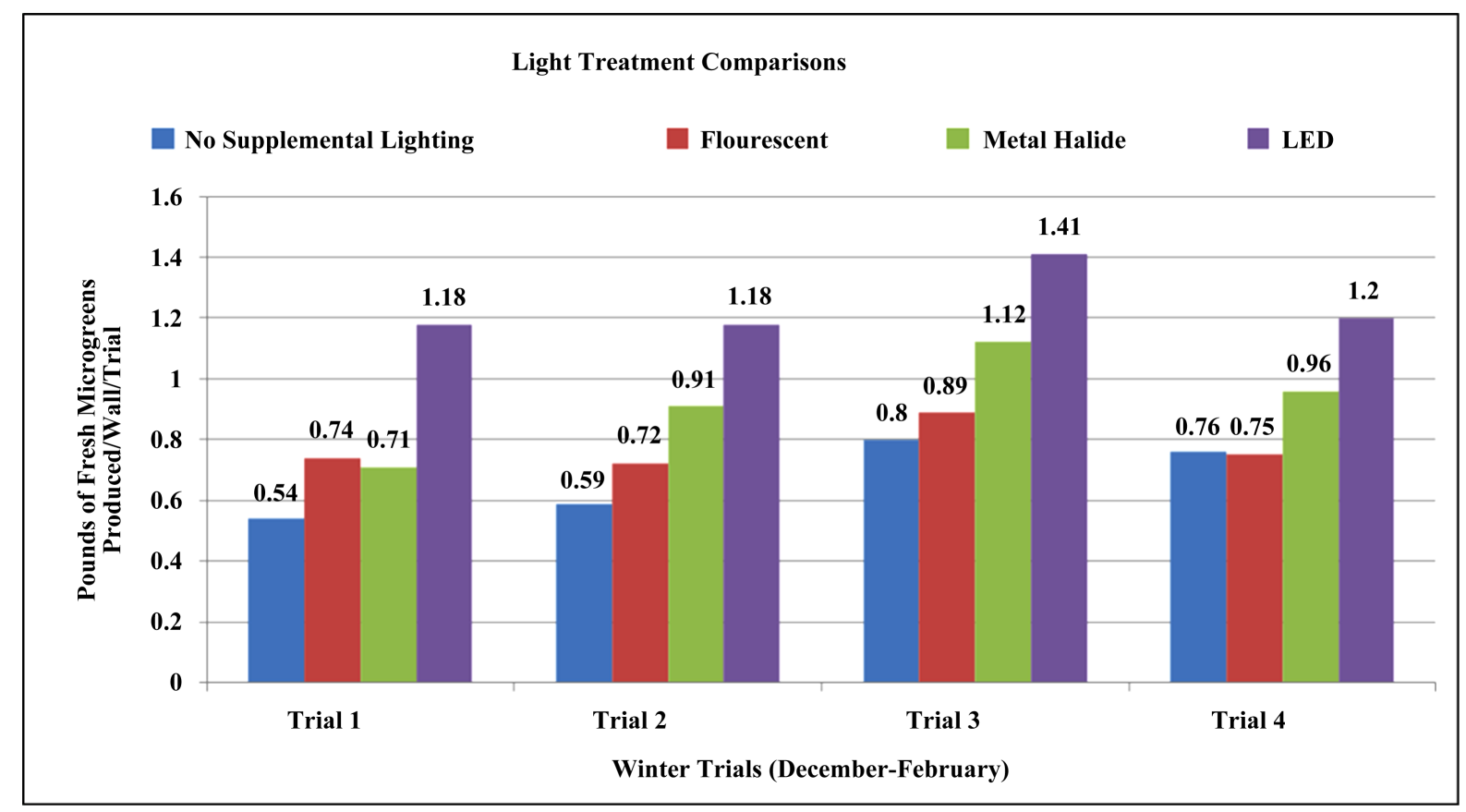

Figure 9. Supplemental lighting. 
\$15/pound: \$9.00

\$25/pound: $\$ 15.00$

\$50/pound: $\$ 30.00$

From the calculations, it is evident that even at \$15/pound, the operational costs of LED lighting pays for itself and is financially feasible, if the significant upfront costs of the lighting fixtures can be incurred.

\section{Conclusions}

The results from the experiments performed support multiple conclusions with regard to operating the Rotating Living Wall systems.

The specific variety of microgreen directly affected the performance of the Rotating Living Wall. In terms of production on a per/trough basis, radish will produce on average approximately four times more than basil. Within the wall system it can produce approximately eight times more. Therefore, the choice of microgreen makes a significant difference not only with production of fresh weight, but the economic viability of the system as well. Although having a variety of microgreens is important from a selling aspect, creating microgreen mixes from high-yielding types will play a significant role in profitability.

The season will directly affect the production yields due to the varying levels of sunlight both observed throughout the trials and recorded through the lighting simulator. Fresh weight data from these trials showed that five times lower light levels found within the winter months correlated to approximately five times lower production yields. Depending on the specific confines of where the Rotating Living Wall functions, lower yields combined with higher utility costs, (heat and electricity for supplemental lighting) may make growing within this time frame prohibitively expensive.

The wall systems produce less microgreen weight per trough compared to the control flat troughs, due to the shaded areas found within the system; approximately $79 \%$ for fresh weight and $74 \%$ for dry weight. Recorded lengths and SPAD readings were lower as well. This ratio does fluctuate throughout the various seasons of the year, due to the changing angle of the sun. However, in terms of production/ $\mathrm{ft} .{ }^{2}$, the walls outperform, producing on average 2.25 times the microgreens per square foot compared to the control flat troughs.

Rotational rate has no effect on production yields based on data collected for fresh weight, dry weight, length, and SPAD. This is due to the "averaging" effect the wall has by periodically rotating the positions of the growing plants. This information is valuable due to the fact that lower rotational rates require less energy for operation and will not affect plant growth.

The physical movement of plants which occurs in the Rotating Living Wall has no effect on production yields based on data collected for fresh weight, dry weight, length, and SPAD. This information is pertinent if continuous movement is desired from an "aesthetics" principle.

When growing microgreens with soilless media, 1.5" can be utilized for plant growth to sustain sufficient rooting structure and nutritional content. Although fresh weight may have a minimal increase with additional media, the cost drastically increases, reducing profitability.

Artificial lighting usage in microgreen production with LED lighting not only can increase yields substantially (by up to two times as exemplified in these past specific trials), but high efficiency allows for relatively low utility costs, improving potential profit. Other types of lighting such as fluorescent and metal halide do have the potential to increase yields, but neither produce nearly the same yields as LED lighting. From the experiments performed throughout the winter season, it became evident that for profitability to be attained when growing with supplemental lighting, the upfront investment of LED lighting fixtures should be made.

Financial viability of a six foot Rotating Living Wall model is possible in State College, PA. However, the system must operate within the correct parameters and conditions to be profitable; especially in winter months where significantly lower light levels are present with increased utility costs. Potential revenue derived from the market potential of microgreens ultimately serves as the driving factor for profitability. Lastly, by constructing a taller model of the Rotating Living Wall with additional troughs, the profitability per square foot of the system could be greatly increased.

\section{Future Direction}

By the year 2050, the population of planet Earth is expected to reach over nine billion people. Solutions need to be implemented now to face this global challenge. There is great promise in controlled environment agriculture, 
urban agriculture, and advances in traditional agriculture. GreenTowers as well as other companies provide not only the tools and innovation for growing in today's urban environments, but also share the message that food security is a challenge that can and needs to be addressed by everyone. Although these solutions and innovations do exist, our global society needs to be pro-active and engaged to implement these solutions. Increasing global food security, fighting world hunger, and ultimately feeding the growing global population cannot be solved through innovative solutions alone. These global challenges must be understood and implemented by our global society to make for a better future.

\section{References}

[1] (2013) World Population Projected to Reach 9.6 Billion by 2050|UN DESA|United Nations Department of Economic and Social Affairs.

http://www.un.org/en/development/desa/news/population/un-report-world-population-projected-to-reach-9-6-billion-by -2050.html

[2] FAO.org. (2014) http://www.fao.org/publications/sofi/2014/en/

[3] FAO, IFAD and WFP (2014) The State of Food Insecurity in the World 2014: Strengthening the Enabling Environment for Food Security and Nutrition. Rome, FAO. http://www.fao.org/3/a-i4030e.pdf

[4] (2015) USDA ERS-Go to the Atlas. http://www.ers.usda.gov/data-products/food-access-research-atlas/go-to-the-atlas.aspx

[5] (2013) USDA ERS-Food Security in the U.S.: Key Statistics \& Graphics. http://www.ers.usda.gov/topics/food-nutrition-assistance/food-security-in-the-us/key-statistics-graphics.aspx

[6] Despommier, D.D. (2010) The Vertical Farm: Feeding the World in the 21st Century. Thomas Dunne Books/St. Martin's Press, New York.

[7] Cox, S. and Van Tassel, D. “Vertical Farming” Doesn’t Stack up. Synthesis/Regeneration Spring 2010: 4+. Global Issues in Context. Web. 5.

[8] Jensen, M.H. (2002) Controlled Environment Agriculture in Deserts, Tropics and Temperate Regions-A World Review. Acta Horticulturae, 578, 19-25. http://www.actahort.org/books/578/578 1.htm

[9] SkyGreens. http://www.skygreens.com/technology/

[10] The Technology Alterrus: http://www.alterrus.ca/verticrop/the-technology/

[11] BrightFarms. http://brightfarms.com/s/\#!/

[12] ZipGrow Towers. Vertical Farming Tech from Bright Agrotech. http://brightagrotech.com/

[13] Freight Farms. Grow Food Anywhere. http://freightfarms.com/

[14] PodPonics. The Future of Farming. http://podponics.com/

[15] Advanced Aerponic System. Vertical Farming. AeroFarms. http://aerofarms.com/why/technology/

[16] (2014) Philips City Farming. http://www.lighting.philips.com/main/application_areas/horticultural/cityfarming/philips-city-farming.wpd

[17] (2014) LED Lighting from GE Helps Farming Go High-Tech in Japan. http://www.gereports.com/post/91250246340/led-lighting-from-ge-helps-farming-go-high-tech-in

[18] Albright, L. (2014) Are “Plant Factories” Viable Greenhouse Alternatives? Greenhouse Management, S17-S23.

[19] Coolong, T. (2012) Microgreens UK Cooperative Extension Service. University of Kentucky College of Agriculture.

[20] Lamp’l, J. (2010) Microgreens Pack Big Flavor. http://www.seattletimes.com/life/lifestyle/microgreens-pack-big-flavor/

[21] FAO.org. Food and Agriculture Organization of the United Nations: Urban Agriculture. http://www.fao.org/urban-agriculture/en/

[22] Johnny’s Selected Seeds. http://www.johnnyseeds.com/c-48-micro-greens.aspx?pagesize=15\&list=1\&pagenum=2

[23] Konica Minolta. http://www.konicaminolta.eu/en/measuring-instruments/products/colour-measurement/chlorophyll-meter/spad-502plus $\underline{\text { introduction.html }}$ 